\title{
Private Information and Altruism in Bidding Roscas
}

\author{
Stefan Klonner* \\ Department of Economics \\ Cornell University
}

\begin{abstract}
:
This paper theoretically and empirically studies how altruism improves allocations in a private information environment where strategic behavior reduces economic welfare. In a bidding Rosca the rank order in which loans are awarded to members of a Rosca group is determined by a sequence of auctions. A theoretical analysis establishes that, in an environment characterized by uncertainty and private information where Rosca funds are used to overcome indivisibilities in investment and outside credit is costly, auction outcomes are more efficient when bidders' preferences are altruistic rather than selfish. A semi-parametric structural estimation of Rosca auctions provides evidence for the presence of strategic costs and altruistic bidding. A parametric structural estimation identifies interactions between group characteristics and bidder altruism. It is found that effective leadership and intra-group diversity are associated with a greater extent of bidder altruism and thus more efficient intra-Rosca allocations.
\end{abstract}

JEL Classification: D44; D82; G20

Keywords: Roscas; Private Information; Auctions

* E-mail: stefan@klonner.de. I am indebted to Susanne van Dillen for introducing me to Roscas and the study village and to Clive Bell, Andrew Foster, Benny Moldovanu, Ashok S. Rai, Robert Townsend, Chris Udry and Quang Vuong as well as seminar participants at Boston University, Brown, Cornell, Heidelberg, UC Irvine, University of Michigan, Penn State, Yale and the World Bank for useful comments. The usual disclaimer applies. Financial support from the German Academic Exchange Service (DAAD) is gratefully acknowledged. 


\section{INTRODUCTION}

It is widely recognized that risk, information asymmetries, and uncertainty form an integral part of life for villagers in low income countries. Much research has been devoted to the analysis of particular institutions and strategies through which households insure against such risks. ${ }^{1}$ On the other hand, Townsend (1994) and various other authors have used income and consumption data to explore to what extent models of full or partial insurance are able to explain observed consumption of village households. Empirical work which explicitly provides evidence on the existence of information asymmetries is, nevertheless, still rare. Even less is known on whether the constraints created by information asymmetries systematically depend on other characteristics of the economic and social environment. As Ligon (1998) concludes, "future empirical work should take seriously the possibility that private information plays an important role in shaping the allocations and institutions of village economies.”

On the other hand, there is growing experimental evidence suggesting that models of purely selfish economic actors fail to explain observed individual behavior. Sobel (2005) reviews several studies, including dictator and public goods provision games, which conclude that subjects' preferences exhibit some form of interdependence, meaning that individual utility depends not only on the payoff to the individual herself but also on the payoffs to other players.

While there has been recent empirical research on how private information constrains efficiency in village economies, this paper is the first to establish how altruism as a form of

\footnotetext{
${ }^{1}$ See Fafchamps and Lund (2003), Kochar (1999), Pandey (2004), Rosenzweig and Binswanger
} (1993), Rosenzweig and Stark (1989), Rosenzweig and Wolpin (1993), and Udry (1994) for examples. 
preference interdependence can improve efficiency in the presence of private information. I study bidding Roscas (rotating savings and credit associations) in a South Indian village. I first show how auction outcomes are more efficient when participants in these Roscas are altruistic rather than selfish. Then I provide evidence for such altruistic bidding using semi-parametric structural estimation. Finally, using parametric structural estimation, I find that certain group characteristics such as effective leadership and diversity are associated with greater altruism.

The institution studied, the bidding Rosca, provides funds for substantial investments, agricultural as well as non-agricultural. The rules of a bidding Rosca allow allocations to respond to individual-specific uncertainty about investment opportunities in the presence of private information. More specifically, a bidding Rosca is a revolving group savings and credit scheme which uses competitive bidding to determine the rank order in which loans are awarded to Rosca members. The higher the winning bid of an auction, the higher the interest rate implicit in the loan awarded to the auction's winner. The auction mechanism thus allows a bidding Rosca to allocate a loan flexibly to the member with greatest concurrent need for funds. ${ }^{2}$

Using qualitative information from a field survey of bidding Roscas, I develop a theoretical model of sequential Rosca auctions, which explicitly incorporates individual-specific uncertainty and private information, and which allows for interdependence of bidders' preferences. As in Klonner (2003), each bidder privately observes a new signal before each auction. As in Kovsted and Lyk-Jensen (1999), funds are used for a lumpy investment and Rosca members have to raise costly outside funds to supplement the funds raised from the Rosca. In this

\footnotetext{
${ }^{2}$ Calomiris and Rajaraman (1998) were the first authors to point out the event insurance role of bidding Roscas among individuals who face unpredictable needs for funds.
} 
framework, bidding creates a strategic cost because the higher the winning bid, the larger the amount the winner of an auction has to borrow from outside to finance her investment project. Unlike Kovsted and Lyk-Jensen (1999), who consider a sequence of first price sealed bid Rosca auctions, I model a sequence of open ascending Rosca auctions, which is the auction format observed in the data underlying this study. Moreover, this is the first attempt to model private value auctions with bidders whose preferences are interdependent. Within this framework, I show that expected winning bids, and thus the strategic cost generated by Rosca auctions, are smaller when bidders’ preferences are altruistic, i.e. positively interdependent.

In the econometric part of the paper, I first develop a semi-parametric structural procedure which delivers estimates of fundamental parameters of the theoretical model without making assumptions on the underlying stochastic process. With a unique dataset of 23 Rosca groups and 149 Rosca auctions from a village in south India, I find evidence for the presence of strategic costs created by the auctions and positive preference interdependence.

Second, I estimate a parametric structural econometric model of Rosca auctions, which allows to identify how bidder altruism interacts with different characteristics of Rosca groups. I find that bidding is more altruistic, and thus strategic costs smaller, in groups headed by an experienced foreman and in groups which are more diverse in terms of caste affiliation of their members.

The rest of this paper is organized as follows. In Section 2, I describe in detail the institution studied and the empirical setting. Summary statistics and reduced form regression results are also provided. Section 3 develops a theoretical model of Rosca auctions. Bidding equilibria with bidders whose preferences are interdependent are derived and it is shown that altruism decreases the strategic cost of bidding. In Section 4, I estimate a structural econometric model of Rosca auctions. A semi-parametric analysis provides evidence for the presence of 
welfare losses due to strategic behavior and deviations from purely selfish behavior. More detailed results are obtained in a subsequent parametric analysis. Section 5 summarizes the findings and offers conclusions.

\section{Bidding Roscas and Empirical SETtING}

In general terms, a Rosca can be defined as 'a voluntary grouping of individuals who agree to contribute financially at each of a set of uniformly-spaced dates towards the creation of a fund, which will then be allotted in accordance with some prearranged principle to each member of the group in turn' (Calomiris and Rajaraman, 1998). Once a member has received a fund, also called a pot, she is excluded from the allotment of future pots until the Rosca ends. In a random Rosca, a lot determines each date's 'winner' of the pot. In a bidding Rosca, a sequence of auctions determines the rank order. In a Rosca auction, the highest bid wins the pot and the price the winner pays is distributed among the other bidders. In a third, empirically relevant, allocation mechanism, the decision on each period's allocation of the pot is left to the Rosca organizer (Handa and Kirton, 1999).

In the south-east Indian state of Tamil Nadu with a population of 62 million in 2001, the turnover in registered Roscas alone, which are mostly of the bidding variety, equaled 100 billion Rupees, about 2.5 billion US dollars, in 2000 (Ganga-Rao, 2001), which compares to aggregate bank deposits of 66 billion Rupees (Reserve Bank of India, 2000). These statistics, however, rather underestimate the importance of this institution in south India as, in rural areas, Roscas are extremely popular but almost never registered.

The sample of bidding Roscas underlying this study is from a village (henceforth referred to as "E”), which is located in a fertile river basin in the southern part of Tamil Nadu. River irrigation facilitates two paddy harvests per year, one in autumn and one in winter. The village 
population numbers about 1000, comprising about 230 households, of which 48 belong to scheduled castes (or SCs for short) and live in a so-called colony about 500 meters away from the main village. The village has a post office but no bank branch. Although male adult literacy is at $57 \%$ and bus connections to two nearby towns with several banking facilities are frequent, comparatively inexpensive and much used, financial transactions with banks play a small role for the three-fifths of village households whose primary income source is agriculture. The only regularly mentioned formal financial transaction within this group is a loan for agricultural inputs from an agricultural co-operative (see van Dillen, 2004).

At the time of the data collection in January and February of 2001 there were 19 organizers of bidding Roscas in E. Of these, 11 were willing to participate in the survey. ${ }^{3} \mathrm{I}$ included all their Roscas which were currently going on or had ended not earlier than after the autumn harvest of 1999, and for which written records were available. This yields information on 23 Roscas and 149 auctions. All of these groups involve two meetings per year, one after each harvest, where harvests typically occur in September and February.

Each of these Roscas works as follows. At each meeting of the group, each of the members pays the stipulated contribution to the organizer. Then an oral ascending auction takes place, in which only those members who have not received a pot at any of the preceding meetings are entitled to bid. The highest bidder obtains the collected contributions, or pot, minus the winning bid, which is shared equally by the losing bidders of that auction. As each member

3 Thus the sample is not entirely representative for the village. In general an organizers' willingness to respond may be correlated with other individual characteristics, such as wealth, age, or the capability to conduct a Rosca business profitably. 
receives exactly one pot in the course of one Rosca cycle, a Rosca has as many meetings as members. At the last meeting there is no auction, as only one member is eligible to receive the pot. Consequently, the last pot is awarded without any deduction.

To illustrate these rules, consider the following three person Rosca which meets three times. Each participant contributes Rs. 10. Suppose the winning bid at the first meeting is Rs. 8. Each of the members other than the winner of the auction receives a dividend of Rs. 4 . The recipient of the first pot effectively has a net gain of Rs. 12 (i.e. the pot less the bid less his contribution). Suppose that at the second meeting (when there are 2 eligible bidders) the winning bid is Rs. 6. This bid is transferred in full to the loser of that auction, as the winner of the first pot is not entitled to share the benefits from subsequent winning bids. The net payoffs are depicted as:

Round $\quad 1 \quad 2 \quad 3$

Winning Bid $\quad 8 \quad 6 \quad 0$

First Recipient $\quad 12 \quad-10 \quad-10$

Second Recipient $\quad-6 \quad 14 \quad-10$

Third Recipient $\quad-6 \quad-4 \quad 20$

For each auction in the sample, the winning bid, the winner's use of the money from the pot, and whether this purpose was his private information during the auction was recorded. Moreover, for each Rosca in the sample, the contribution of each member per round, the number of participants, the group's caste composition, the number of Roscas the organizer had operated previously, and the number of Roscas he had completed with the same group were recorded. Some summary statistics are set out in Table 1 . Note that each observation in this data set refers to the outcome of one auction. Thus, for example, if at the time of the interview in a Rosca with ten participants six auctions had taken place, this Rosca contributes six observations to the data 
set. As the Rosca-specific variables take the same respective values for all of these six observations, Table 1 also includes summary statistics of group characteristics with the group as the unit of observation.

Contributions are substantial in these Roscas. To put the numbers into perspective, the daily minimum wage for an agricultural worker was Rs. 40 at the time of the data collection, implying that in some of the groups the bi-annual contribution per participant amounts to more than 100 daily minimum wages. The Roscas are, moreover, of fairly long duration. With a membership of ten to seventeen and two rounds per year, they last for five to eight years. The majority of members come from non-SC households and, in regard of the fact that SC's account for 21 percent of village households, scheduled caste households are clearly underrepresented as Rosca members. Organizers stated that participation of SC households is a fairly recent phenomenon in E.

All of the organizers of Roscas are from non-SC households and are, as casual observation during the interviews suggests, relatively wealthy. In these Roscas, the organizer plays a central role. He invites or admits participants, is responsible for the collection of contributions and guarantees timely payment to each winner of an auction. In return he is a special member of the group who receives the second pot in full, i.e. there is no auction in the second round. In all other rounds, he keeps a commission of 1 to $2.5 \%$ of the pot. Organizers of Roscas in this sample do not have a long record of experience. On average, an organizer completed less than three Roscas before starting the one on which he was interviewed.

Turning to auction-specific characteristics, the fact that the average number of bidders per auction, 7.07, is substantially smaller than the average Rosca duration, 11.8 , is due to the fact that 14 of the 23 groups in the sample were still ongoing at the time of the interview. As would be 
expected in a sufficiently large sample, about half of the auctions recorded occurred after a winter (as opposed to an autumn) harvest.

A unique feature of these data is that it contains the purpose for which the winner of an auction used the pot and information on whether that purpose was known to the other bidders during the auction or not. Organizers assured that they were able to assess this latter issue competently. The finding that in only roughly a quarter of auctions other bidders were aware of the winner's intention during the auction is in stark contrast with much of the literature on village economies where it is assumed that information flows freely (e.g. Udry, 1991). In this connection it should also be mentioned that organizers as well as a vast majority of Rosca participants whom I also interviewed ascertained that typically each bidder goes into the auction with a clear idea of what he would use the funds for were he to win the auction.

The purpose categories for which pots are used together with the information structure are set out in Table 2. Notice that, ex post, the winner's use of funds was revealed in 86 percent (128 occurrences) of all auctions. Thus, while in most cases the use of funds becomes known to villagers ex post, a winner's ex ante intention remained private information in $73 \%$ of all auctions. Important differences across purpose categories arise, however. Of the 128 observations for which the use of funds is ex post known, half can be considered directly productive investments, where the bulk is for agricultural purposes. It is striking that the winner's purpose was commonly known in only 4.7 percent of these auctions. On the other hand, when funds are used to marry a daughter, that purpose is public information ex ante in more than 75 percent of auctions. This finding is in accordance with qualitative statements made by both organizers and participants. All interviewees agreed that, on the one hand, if funds are obtained for a profitable business purpose, it is advantageous to keep the intended use of Rosca funds secret. It was stated that, while the use of funds for a productive purpose may still be verifiable ex post, its exact 
profitability is typically not and that in such cases the competitive aspect of bidding is needed to isolate the bidder with the most profitable use for the funds. On the other hand, it was agreed that it is considered inappropriate behavior to raise the bid excessively when it is known that one of the bidders has an economic "emergency", that is a pending, not business-related financial obligation. A daughter's wedding, for which the parents have to provide dowry and finance the festival, was mentioned as the prime example of an emergency. Other instances are the obligation to settle overdue debt with a moneylender and the urgent repair of one's dwellings. While, according to Table 2, the winner's purpose was commonly known in only one third of the cases of housing investments in general, Table 3 demonstrates that information is mostly private when funds are used for the purchase or construction of a house while information is public for two thirds of all housing renovations. If, by implicit mutual understanding, bidding goes less high in such instances, then a bidder with a publicly known "emergency" can obtain a pot at more favorable conditions, which supports the hypothesis that observable events are better insured than unobservable ones (as in Fafchamps and Lund, 2003).

Another important piece of qualitative evidence comes from a sample of 21 participants in bidding Roscas who unanimously stated that it is crucial to be able to obtain a pot when there is an unforeseen opportunity or 'emergency', and that, for this reason, random Roscas are useless. In 10 out of 14 cases where the respondent had already obtained a pot of an ongoing Rosca, the respondent stated to not have had a particular idea what to use the funds for at the time of joining the group, or to have used the funds for a different purpose than originally intended. In three other cases where intended and actual use of Rosca funds coincided, all three respondents stated that they were initially uncertain about the timing (in which round to take the pot) of the expenditure. The only case in which intended and actual use of funds, as well as intended and actual timing of obtaining the pot coincided, was a respondent who took the first pot to repair his 
house. Taken together, these findings provide substantial evidence for the importance of uncertainty about either the nature or the timing of the event for which Rosca funds are required.

Figure 1 depicts the minimum, mean and maximum of recorded relative winning bids by number of bidders, where a relative bid is defined as the absolute bid amount divided by the pot amount. While, conditional on any number of bidders, there is substantial variation in winning bids, average winning bids clearly decrease as there are fewer bidders. This is easily understood when three complementary effects are taken into account. First, the number of bidders is inversely related to the round in which the corresponding auction takes place. Consequently, the winner of an auction with more bidders is granted a longer duration loan. Given that the winning bid reflects the interest payment for the early receipt of funds and provided that the interest rate for long and short loans in a Rosca is similar, the recipient of an early pot pays more interest in absolute terms, and thus a higher winning bid, than a later recipient. Second, as an early recipient has paid fewer previous contributions, an early recipient's net loan amount is larger than that of a later recipient. Finally, the earlier the round, the larger the number of bidders, which increases the competitiveness of the auction.

Both organizers of and participants in bidding Roscas pointed out that excessive bidding is bad for the welfare of the group. It was, instead, considered more advantageous the more an auction allocates to the winner, who would have a good purpose for using the funds. In contrast, money disbursed as side-payments to the losing bidders would usually rather be consumed, which was considered an inferior purpose.

To see to what extent winning bids can be explained by group and auction characteristics, Table 4 contains results of an OLS regression of the relative winning bid (in percentage points) on group and auction-specific characteristics. The significant positive relationship between monthly contribution and relative winning bids suggests that, other things held constant, bidding 
is more competitive in groups with more at stake. According to the point estimate, relative winning bids in groups with a biannual contribution of Rs. 5,000 exceed those in groups with a contribution of Rs. 1,000 by 5.8 percentage points. The caste composition of a group, on the other hand, is not a statistically significant predictor of winning bids. Winning bids are significantly smaller, the larger the number of Rosca cycles previously completed by the same group. With each cycle completed, the average relative winning bid decreases by 2.21 percentage points. A negative, albeit insignificant, relationship also exists between winning bids and the experience of the organizer, which is measured by the number of Roscas he had completed previously.

In accordance with the previous discussion, winning bids are increasing in the number of bidders in an auction. Conditional on the number of bidders, winning bids are higher in firstround auctions. This can be explained by the fact that there is no auction in the second round, where a full pot goes to the organizer. Provided that bidders discount future payoffs, the option value of being able to bid in the next auction is thus smaller in a first-round auction as a losing bidder cannot bid for another pot half a year later but, instead, has to pay a full contribution and wait for another half year for the next auction. A similar argument applies to winter auctions as there are seven months between a winter and an autumn round but only five between an autumn and a winter round.

The most interesting finding among the set of explanatory variables that capture auctionspecific characteristics is that winning bids are smaller in auctions where the winner's purpose is publicly known before the auction. As elaborated above, these are mostly situations in which a bidder faces an ex-ante verifiable financial emergency. This finding appears to support the claim of villagers that bidding is more moderate when a bidder is known to face a financial emergency. 


\section{THEORY}

In this section the observations from the previous section are used to develop a benchmark model that formalizes bidding in a Rosca auction. Section 3.1 discusses the assumptions and the auction protocol governing the bidding in the sample Roscas. As in Kovsted and Lyk-Jensen (1999), it will be assumed that participants use Rosca funds to finance an indivisible investment project and that outside credit is costly. In contrast to their model and in line with the qualitative evidence provided above, I will assume that each Rosca member privately observes a different rather than the same signal in each round. Further, while Kovsted and Lyk-Jensen analyze first price sealed bid auctions, I derive bidding equilibria for open ascending auctions.

In Section 3.2, the bidding equilibrium is derived under the assumption that each bidder maximizes his expected income. Section 3.3 extends this benchmark by considering bidders with interdependent utility functions. It is shown that allocations in a Rosca with members whose

utility functions exhibit positive interdependence generate a (ex ante) larger welfare for each member than when Rosca members are selfish.

\subsection{A Model of Rosca Auctions}

Consider a Rosca auction with $K$ bidders and a pot of 1 Rupee with an oral ascending bid auction in place. Denoting the last bid made by $b^{w}$, say, the winner has a payoff of $1-b^{w}$, while each loser receives $b^{w} /(K-1)$.

Suppose that each individual is a risk neutral utility maximizer who discounts future income by a factor of $\delta \leq 1$. Each individual participates in only one bidding Rosca at a time. After each harvest, each Rosca participant has access to an indivisible investment project which 
costs 1 Rupee. ${ }^{4}$ At the same time, each Rosca participant privately observes the profit of her investment project. This random variable, denoted by $R$, is independently and identically distributed over participants and rounds according to the smooth cumulative distribution function (cdf) $F(r)$ with support $[\underline{r}, \bar{r}]$, meaning that each participant observes a different draw of $R$ in each period. This assumption reflects the uncertainty about the nature and/or timing of events for which Rosca funds are needed (see the previous section). The profit from the investment of one Rupee creates an instantaneous utility of $R$. Outside credit is available to finance the gap between the funds received from the Rosca and the cost of the investment project at an instantaneous cost of $c>1$ per Rupee borrowed. ${ }^{5}$

In E, Rosca auctions are invariably of the oral ascending bid (OA) form, i.e. those participants who have not yet received a pot meet and cry out successive oral bids until only one bidder, the winner, remains. In accordance with much of the literature on auctions, I model the OA-Rosca auction as a so-called button auction, where each bidder presses a button as the standing bid continuously increases. A bidder drops out of the bidding process once he releases

4 The assumption that Rosca funds are used to overcome indivisibilities is in accordance with the qualitative evidence form the study village (see Section 2). Indivisibility also underlies the Rosca models of Besley et al. (1993), Kovsted and Lyk-Jensen (1999), and Anderson and Balland (2002).

5 This assumption is supported by the fact that informal credit appears to be readily available to Rosca participants in E. The majority of respondents in the Rosca participant sample reported credit transactions with moneylenders, who appear to operate competitively. At interest rates of three to five percent per month, such credit is costly, however. 
his button. The auction is over once there is only one bidder still pressing his button. He receives the pot at a price equal to the standing bid at the moment the last one of the other bidders dropped out, $b^{w}$

For the derivation of a bidding equilibrium in the Rosca button auction, it will be useful to consider a second price, sealed bid (SPS)-Rosca auction. In such an auction, each bidder submits a bid in a sealed envelope. The highest bid wins and the winner pays a price equal to the second highest bid submitted. For simplicity, I will assume that in the button auction a bidder does not observe how many other bidders are still holding down their buttons. ${ }^{6}$ Each bidder's problem is to decide when to release her button. Suppose that each bidder releases her button at a standing bid equal to her bid in the SPS-Rosca auction. If all bidders follow this rule, the payoffs to all participants are equal in the SPS and the OA-Rosca auction. Further, since, during the button auction, by assumption, a bidder does not obtain any further information than a bidder of a SPSRosca auction has, the reduced normal form games corresponding to the second price, sealed bid and the oral ascending bid Rosca auction are identical. Thus they are strategically equivalent, which implies that the equilibrium of the SPS-Rosca auction is also an equilibrium of the OARosca auction.

${ }^{6}$ Deltas (2002) studies open ascending knockout auctions in bidding rings, in which bidders face an optimization problem similar to the one occurring in a Rosca auction. Using his techniques, it can be shown that the symmetric equilibrium of an OA-Rosca auction derived under the set of assumptions just made remains unchanged when a bidder can observe how many other bidders are still holding down their buttons. 


\subsection{Income-Maximizing Preferences}

In this section a symmetric, increasing, Bayesian-Nash equilibrium bidding function $b_{K}(r)$ for an SPS Rosca auction is derived for the case where each bidder maximizes her own expected payoffs. The analysis is at the interim stage, i.e. after each bidder has privately observed her profit and before bids are submitted. At this stage each bidder's problem is to determine a bid which maximizes her expected utility based on the information available to her. In accordance with empirical observation, I will focus on a situation where the winner of the auction invests while each losing bidder consumes her payoff.

In an auction with $K$ bidders, the auction's winner has an ex post utility of $r-c b^{w}$, while each loser's utility equals $b^{w} /(K-1)+\widetilde{\Pi}_{K}$, where $\widetilde{\Pi}_{K}$ is the continuation value of being eligible to receive a pot or share the winning in each of the remaining $K-1$ rounds. Since the winner of the auction cannot bid for a pot nor enjoy a share in the winning bid in subsequent rounds, the winner's continuation value is equal to zero.

$\widetilde{\Pi}_{K}$ is defined recursively. Specifically, $\widetilde{\Pi}_{1}=E[R]$ because the recipient of the last pot receives the full balance needed to invest and, in expectation, has a profit of $E[R]$. From the perspective of a bidder in an auction with $K+1$ bidders, where $K \geq 1$, the recursion formula is

$$
\widetilde{\Pi}_{K+1}=\delta\left\{\frac{1}{K}\left(E\left[R_{K: K}\right]-c E\left[b_{K}\left(R_{K-1: K}\right)\right]\right)+\frac{K-1}{K}\left(E\left[\frac{b_{K}\left(R_{K-1: K}\right)}{K-1}\right]+\widetilde{\Pi}_{K}\right)\right\},
$$

where $R_{J: K}$ denotes the $J$ 'th lowest order statistic in a random sample of size $K$. Given that the outcome of the following auction with $K$ bidders is determined by a symmetric, increasing bidding function $b_{K}(r), 1 / K$ is the ex ante probability of winning the following auction. The 
winner's profit of that auction is distributed as the highest order statistic of a sample of size $K$ while the winning bid is a function of the second highest observed profit. $(K-1) / K$ is the ex ante probability of losing that auction. Each loser enjoys part of the winning bid, which is shared by the $K-1$ losing bidders, and is entitled to bid subsequently which is why the term $\widetilde{\Pi}_{K}$ is added to the expected payoff of a losing bidder.

Next I formalize the assumption that only the auction's winner invests. This requires, first, that the utility from incurring a loan of $b^{w}$ at a cost of $c$ per Rupee and investing is greater than the utility from consuming the net payoff of $1-b^{w}$,

$$
r^{w}-c b^{w} \geq 1-b^{w}
$$

for all configurations of $r^{w}$ and $b^{w}$ supported by a symmetric, increasing equilibrium, where $r^{w}$ denotes the profit observed by the auction's winner. As the focus here is on a SPS auction with a symmetric, increasing bidding function $b_{K}()$, we have that $b^{w}=b_{K}\left(r_{K-1: K}\right)$. Further, $r^{w}=r_{K: K}>r_{K-1: K}$, which implies that (1) is equivalent to

$$
r-1 \geq(c-1) b_{K}(r) \text { for all } r \text {. }
$$

The second requirement is that each loser consumes her payoff from the auction. This is equivalent to the condition that the utility from consuming $b^{w} /(K-1)$ is greater than the utility from incurring a loan of $1-b^{w} /(K-1)$ and investing,

$$
\frac{b^{w}}{K-1} \geq r-c\left(1-\frac{b^{w}}{K-1}\right)
$$

for all configurations of $r$ and $b^{w}$ supported by a symmetric, increasing equilibrium. By an argument analogous to the one used in the derivation of (2), (3) may be written as

$$
\frac{b_{K}(r)}{K-1} \leq \frac{c-r}{c-1} \text { for all } r .
$$


Turning to a bidder's maximization problem, denote by

$$
\Pi_{k}\left(r_{k}, b_{1}, \ldots, b_{K}\right)=\left\{\begin{array}{c}
r_{k}-c b_{K-1: K}, \text { if } b_{k}=b_{K: K} \\
\frac{1}{K-1} b_{K-1: K}+\widetilde{\Pi}_{K}, \text { if } b_{k}<b_{K: K}
\end{array}\right.
$$

the ex post utility of bidder $k$ as a function of her profit and the collection of bids $b_{1}, \ldots, b_{K}$. Without loss of generality, the equilibrium bidding function $b_{K}^{e}(r)$ is obtained as the solution to $\max _{b} E\left[\Pi_{1}\left(r, b, b_{K}^{e}\left(R_{2}\right), \ldots, b_{K}^{e}\left(R_{K}\right)\right)\right]$ for all $r$. The following proposition characterizes the corresponding bidding equilibrium. All proofs are relegated to the appendix.

Proposition 1

If $b_{K}^{e}(r)=\frac{K-1}{1+c(K-1)}\left(r-\widetilde{\Pi}_{K}+\int_{r}^{\bar{r}}\left(\frac{1-F(t)}{1-F(r)}\right)^{1+c(K-1)} d t\right)$ satisfies (2) and (4), then $b_{K}^{e}()$ is the increasing, symmetric Bayesian-Nash equilibrium bidding function of a second price, sealed bid Rosca auction with K income-maximizing bidders. In this equilibrium, only the auction's winner invests.

To provide some intuition for the equilibrium bidding function, notice that $b_{K}^{0}(r)=\frac{K-1}{1+c(K-1)}\left(r-\widetilde{\Pi}_{K}\right)$ is the bid that equalizes the ex-post utilities from winning and losing the auction for a bidder who observes a profit of $r$,

$$
b_{K}^{0}(r)=\left\{b: r-c b=\frac{b}{K-1}+\widetilde{\Pi}_{K}\right\} \text {. }
$$


In accordance with the literature on standard auctions, I will refer to $b_{K}^{0}(r)$ as the valuation of a bidder with profit $r$ for the pot. This implies that, in the non-altruistic equilibrium just characterized, each bidder bids above her valuation (except when she observes $\bar{r}$ ). The reason is that the revenue generated by the auction is transferred to the losers of the auction. This effect is absent in standard auctions where the revenue goes to a third party seller. Therefore, in contrast to standard private value auctions, it is not an equilibrium of a SPS-Rosca auction to bid one's valuation. Notice that the incentive to bid higher than one's valuation does not exist for a bidder who observes $\bar{r}$ as, in equilibrium, she does not enjoy a side payment with probability one. ${ }^{7}$

At this point it is also in order to comment on conditions (2) and (4), which ensure that only the auction's winner invests. Since it is difficult to assess how binding these restrictions are in general, I provide an example with the uniform distribution, where $\delta=0.5$ and $K=2$. Substituting $b_{2}^{e}($ ) into (2) and (4) demonstrates that, loosely speaking, $c$ has to be sufficiently large relative to $\bar{r}$ to ensure that losers always find it advantageous to consume, while $c$ cannot exceed $\underline{r}$ by too much to ensure that the winner always invests. A numerical example where both of these requirements are met is $\underline{r}=1.4, \bar{r}=1.6$ and $c=2$.

Proposition 1 demonstrates that the efficiency of allocations generated by the bidding mechanism (i.e. the pot is allocated to the bidder with the highest profit) comes at the cost of a loss in welfare (or, more accurately, ex ante expected utility). To be precise, in each auction an

${ }^{7}$ Rosca auctions share this property with so-called auctions with price-proportional benefits to bidders (see Engelbrecht-Wiggans, 1994). Important applications of such auctions are bidding rings (Deltas, 2002) and toehold and takeover battles (Bulow et al., 1999). 
amount of $(c-1)$ times the winning bid is extracted from the group by, for example, a money lender. In the sequel, I will refer to this amount as the strategic cost of a Rosca auction. This feature of the model is well in accordance with the observation that, in general, villagers find it more advantageous the more of the pot an auction allocates to the winner.

\subsection{Interdependent Preferences}

In the environment in which the Roscas studied in this paper operate, there are reasons to expect departures from the just derived bidding equilibrium. As described in Section 2, in these Roscas, bidders interact repeatedly as documented by the number of Rosca cycles completed previously by a group, organizers have a concern that bidding in their groups is not excessive, and individual behavior in Rosca auctions likely affects a participant's reputation outside the Rosca. Such factors may mitigate the strategic costs of bidding and thus increase the welfare derived from participating in a Rosca. Moreover, there is a substantial body of experimental evidence suggesting that income maximization fails to explain observed behavior, even in anonymous oneshot interactions. ${ }^{8}$ A natural and empirically tractable way of incorporating these considerations is to allow bidders' preferences to be interdependent. More specifically, I consider interdependent preferences of the kind suggested by Ledyard (1995) as an explanation of the results of public goods contribution games.

To make precise how the model of the preceding subsection is modified, recall that, with selfish preferences, $b_{K}^{e}(r)$ solves $\max _{b} E\left[\Pi_{1}\left(r, b, b_{K}^{e}\left(R_{2}\right), \ldots, b_{K}^{e}\left(R_{K}\right)\right)\right]$ for all $r$. In this section, in contrast, I consider a bidder who maximizes a weighted average of her own and other bidders’ expected utilities. Without loss of generality, we may consider bidder 1 whose problem is to

\footnotetext{
${ }^{8}$ See Sobel (2005) for an excellent review of this literature.
} 


$$
\begin{gathered}
\max _{b} \frac{1}{1+(K-1) \mu} E\left[\Pi_{1}\left(r, b, b_{K}\left(R_{2}\right), \ldots, b_{K}\left(R_{K}\right)\right)+\mu \Pi_{2}\left(R_{2}, b, b_{K}\left(R_{2}\right), \ldots, b_{K}\left(R_{K}\right)\right)\right. \\
\left.+\ldots+\mu \Pi_{K}\left(R_{K}, b, b_{K}\left(R_{2}\right), \ldots, b_{K}\left(R_{K}\right)\right)\right],
\end{gathered}
$$

where $\mu$ captures the nature and extent of interdependence. In Sobel's (2005) terminology, bidders whose utility function is characterized by a positive (negative) value of $\mu$ will be referred to as altruistic (spiteful). It is assumed that all bidders of an auction have identical preferences, i.e. $\mu$ is identical across bidders. The following proposition characterizes the corresponding bidding equilibrium.

Proposition 2

For $\mu \leq \frac{(K-1)(c-1)}{1+(K-1)(c-1)}$, if $b_{K}^{a}(r)=\frac{K-1}{1+c(K-1)}\left(r-\widetilde{\Pi}_{K}+\int_{r}^{\bar{r}}\left(\frac{1-F(t)}{1-F(r)}\right)^{\frac{1+(K-1)(K-1) \mu(1-\mu)}{1-(1-1)}} d t\right)$ satisfies (2) and (4), $b_{K}^{a}()$ is the increasing, symmetric Bayesian-Nash equilibrium bidding function of a second price, sealed bid Rosca auction with K bidders with interdependent preferences. In this equilibrium, only the auction's winner invests.

Notice that, within this framework, selfish bidding arises as a special case when $\mu=0$. When $\mu=\frac{(K-1)(c-1)}{1+(K-1)(c-1)}$, we have that $b_{K}^{a}(r)=b_{K}^{0}(r)$, i.e. each bidder bids exactly her valuation for the pot. In general, $b_{K}^{a}(r)$ is decreasing in $\mu$ except when $r=\bar{r}$. As an illustration, Figure 2 depicts bidding functions with spiteful, income-maximizing and altruistic bidders for the numerical example given towards the end of the previous subsection. 
An increase in $\mu$ reduces the amount of the winning bid and thus the strategic cost of the auction with probability one while retaining efficiency in the sense that the pot goes to the bidder with the highest profit. It is thus clear that a group of altruistic Rosca participants enjoys a higher welfare from joining a Rosca than a group made up of selfish individuals. This is summarized in the following corollary.

\section{Corollary 1}

For $c>1$, ex ante expected utility from Rosca participation is strictly increasing in $\mu$.

Notice that this scenario is analogous to a public goods provision game, where interdependence can explain higher (and socially more efficient) contributions than incomemaximizing preferences (see Ledyard, 1995).

To conclude this section, I will discuss the robustness of the result stated in this corollary to the relaxation of some of the assumptions which have been made in the course of the derivations. For considerations of space, proofs of the claims stated here are not given (they are available form the author on request). Instead, the economic intuition is emphasized. First, with the data available it is not possible to identify asymmetries across bidders in the same auction. Therefore, the theoretical analysis is confined to symmetric bidders. Second, when bidders are risk-averse, it continues to hold that altruistic bidders bid less aggressively and enjoy a higher welfare. In the model developed above, risk aversion merely makes bidders bid more cautiously. ${ }^{9}$

${ }^{9}$ Loosely speaking, risk aversion makes a bidder more reluctant to obtain a pot at a price higher than her valuation. 
Third, when outside funds are not supplied completely elastically, i.e. when $c$ is a (possibly increasing) function of the amount borrowed, the valuation $b_{K}^{0}(r)$ will no longer be a linear function of $r$. As long as $c(r)$ is bigger than one for at least some $r \in[\underline{r}, \bar{r}]$, however, interdependence has the same effect on bids and welfare as under the more restrictive assumption of a constant $c$.

Fourth, why does an individual not choose a Rosca with a contribution large enough to avoid the need to resort to costly outside credit or, alternatively, choose a smaller project size once she obtains a pot at a positive winning bid? In this connection it can be shown that, if projects are sufficiently profitable in expectation, the result of corollary 1 continues to hold. In the first case the Rosca member forgoes additional profits because, with positive probability, she ends up consuming a substantial fraction of the funds obtained from the Rosca. In the second case, lower bids imply that the winner of an auction invests more. As the marginal return on each Rupee invested is greater than the marginal utility of a losing bidder from consuming her share of the winning bid, altruism continues to increase welfare. Finally, all derivations rest on the stylized assumption of individual participation in only one Rosca at a time. Evidence from the Rosca participant sample, however, suggests that multiple Rosca membership is rather common (the sample average is 2.1 Roscas per household). While this may affect individual bidding strategies, the statement of corollary 1 continues to hold as long as the winner of an auction has a higher return to each additional rupee obtained from the Rosca than a loser.

\section{Structural Econometric Analysis}

The goal of this section is to infer from observed winning bids how group and auction characteristics interact with the nature of interdependence of bidders' preferences. The empirical analysis has two parts. First, a semi-parametric structural econometric model is derived from the 
theoretical model of the previous section to estimate some key parameters. While this approach has the advantage of delivering inference without requiring the specification of particular functional forms, it does not allow to account for the observed heterogeneity in the data. That group and auction-specific characteristics matter for auction outcomes has, however, been demonstrated in Section 2. Therefore, in the second part of this section, I estimate a parametric structural econometric model, which is able to exploit the heterogeneity in the data and identify how group and auction characteristics interact with bidders’ altruism.

\subsection{Semi-parametric Analysis}

The key parameters of the theoretical model of Rosca auctions developed in Section 3 are $c$, which captures the strategic cost generated by an auction, and $\mu$, the degree of interdependence. Here I empirically identify these parameters without assuming a particular form of $F$, the cdf according to which privately observed profits are distributed. The identification strategy is original and inspired by some recent work of Campo (2005).

The point of departure is the differential equation obtained from the first-order condition associated with maximization problem (5), which characterizes $b_{K}^{a}()$,

$$
\left(1-\phi_{K}\right)(1-F(r)) b_{K}^{a \prime}(r)+f(r)\left[(K-1)\left(r-\widetilde{\Pi}_{K}\right)-(1+(K-1) c) b_{K}^{a}(r)\right]=0,
$$

where $\phi_{K}=(K-1)(c-1) \mu /(1-\mu)$. Notice that $\phi_{K}=0$ captures the case of income-maximizing bidders while, when $\phi_{K}=1$, altruism makes a bidder bid her valuation. Denote by $G_{K}(b)$ the cdf

of bids generated by (6), when $R$ is distributed according to $F($ ). As in Guerre et al. (2000), the following identities hold:

$$
G_{K}\left(b_{K}\right)=G_{K}\left(b_{K}^{a}(r)\right)=F(r),
$$




$$
g_{K}\left(b_{K}\right)=g_{K}\left(b_{K}^{a \prime}(r)\right)=\frac{f(r)}{b_{K}^{a \prime}(r)},
$$

where $b_{K}$ denotes a realized bid in a SPS-Rosca auction with $K$ bidders. Identity (7) is straightforward when the bidding function is monotonically increasing and (8) follows from differentiating (7) with respect to $r$. Substituting (7) and (8) into (6) and solving for $r$ gives

$$
r=\left(c+\frac{1}{K-1}\right) b_{K}+\widetilde{\Pi}_{K}-\left(1-\phi_{K}\right) \frac{1-G_{K}\left(b_{K}\right)}{g_{K}\left(b_{K}\right)},
$$

where $b_{K}$ has been substituted for $b_{K}^{a}(r)$. When all bids are observed, $K, b_{K}, G_{K}\left(b_{K}\right)$ and $g_{K}\left(b_{K}\right)$ are in principle observable $\left(G_{K}()\right.$ can be approximated by the empirical cdf of bids while $g_{K}()$ can be estimated from observed bids by, e.g., Kernel methods), while $r, c, \widetilde{\Pi}_{K}$ and $\phi_{K}$ are unobserved. Substituting $q$ for $G_{K}\left(b_{K}\right)$ and denoting by $r_{q}$ and $b_{K q}$ the associated quantiles of the underlying distributions of $R$ and $b_{K}^{a}(R)$, we obtain

$$
r_{q}=\left(c+\frac{1}{K-1}\right) b_{K q}+\widetilde{\Pi}_{K}-\left(1-\phi_{K}\right) \frac{1-q}{g_{K}\left(b_{K q}\right)} .
$$

As (10) holds for alternative values of $K, K_{1}$ and $K_{2}$ say, identification can be achieved by evaluating

(11) $\left(c+\frac{1}{K_{1}-1}\right) b_{K_{1} q}+\widetilde{\Pi}_{K_{1}}-\left(1-\phi_{K_{1}}\right) \frac{1-q}{g_{K_{1}}\left(b_{K_{1} q}\right)}=\left(c+\frac{1}{K_{2}-1}\right) b_{K_{2} q}+\widetilde{\Pi}_{K_{2}}-\left(1-\phi_{K_{2}}\right) \frac{1-q}{g_{K_{2}}\left(b_{K_{2} q}\right)}$ at alternative values of $q$. Notice that $\widetilde{\Pi}_{K_{1}}$ and $\widetilde{\Pi}_{K_{2}}$ cannot be identified separately from (11) as these two terms enter the equation additively. Thus, for identification of the unobserved quantities $c, \phi_{K_{1}}, \phi_{K_{2}}$ and $\Delta_{\widetilde{\Pi}} \equiv \widetilde{\Pi}_{K_{1}}-\widetilde{\Pi}_{K_{2}}$, (11) needs to be evaluated at four different values of $q$. Notice that, in principle, (11) overidentifies these parameters as this equation can be evaluated at arbitrarily many values of $q$. 
Since auctions are of the oral ascending kind in the present application, for each auction only the winning bid is recorded while the remaining $K-1$ bids remain unobserved. As the winning bid is the second highest order statistic of a sample of $K$ bids, the distribution function of bids in an auction with $K$ bidders, $G_{K}()$, can be estimated from the empirical distribution function of winning bids in an auction with $K$ bidders through the following identity, which defines the cdf of the second highest order statistic of a sample of size $K, G_{K-1: K}()$,

$$
\left(G_{K}(b)\right)^{K-1}\left(K-(K-1) G_{K}(b)\right)=G_{K-1: K}(b) .
$$

Further, $g_{K}()$ is obtained from $g_{K-1: K}()$ through the identity

$$
g_{K}(b)=\frac{g_{K-1: K}(b)}{K(K-1)\left(1-G_{K}(b)\right)\left(G_{K}(b)\right)^{K-2}},
$$

where $g_{K-1: K}()$ is estimated by Kernel methods from winning bids in auctions with $K$ bidders.

Application of this semi-parametric approach just portrayed requires that, conditional on $K$, bids are identically distributed. As the reduced form analysis of winning bids in Section 2 suggests, however, heterogeneity across groups and auctions is an important feature of the data. To eliminate at least part of the auction-specific heterogeneity, I will use an observation only if the winner's purpose was his private information and if the auction is not the first auction in a Rosca. ${ }^{10}$ I moreover require that, for a given number of bidders, at least ten observations are available. This leaves us with $K$ equal to 5, 6,7 and 8, for which there are 12, 15, 10 and 18 observations available, respectively. To provide some intuition of how winning bids are

${ }^{10}$ Recall that in all of the sample Roscas, no auction takes place in the second round. Therefore, conditional on the number of bidders, bids in first auctions are distributed differently than bids in later auctions. 
distributed, Figure 3 depicts the estimated densities of winning bids from auctions with six and eight bidders, respectively.

Equation (11) is evaluated at values of $q$ of $0.4,0.5,0.6$ and 0.7 . These values are chosen because, by virtue of (12), relatively more information is available for larger realizations of bids. The results of a simultaneous estimation of $c, \Delta_{\widetilde{\Pi}}, \phi_{K_{1}}$ and $\phi_{K_{2}}$ for all six permutations of $K_{1}$ and $K_{2}$ are set out in Table 5. As the statistical properties of these parameter estimates have not been derived in the extant literature and doing so is well beyond the scope of this paper, the results comprise only point estimates. The first four rows of columns 1, 2 and 3 contain the estimates for auctions with five and six, five and seven, and five and eight bidders, respectively. The convention is that $K_{1}>K_{2}$. For five of the six permutations, $c$ is estimated negative, which suggests that either the model is inappropriate for these data, which may be due to non-identically distributed bids, or there is not enough data to obtain reasonably unbiased estimates as the procedure used here may have poor small sample properties. ${ }^{11}$

In view of this, two restricted versions of (11) are estimated subsequently. The first one imposes non-altruistic behavior on bidders, that is both $\phi_{K_{1}}$ and $\phi_{K_{2}}$ are set equal to zero. ${ }^{12}$ The results are set out in Table 6. The parameter $c$ is now estimated greater than one in four of the five

11 Using a closely related estimation strategy, Bajari and Hortacsu (2004) encounter similar problems in an attempt to recover bidders’ degrees of risk aversion from experimental data.

12 As the remaining two parameters are overidentified when (11) is evaluated at four distinct values of $q$, as in Campo (2005) parameter estimates are obtained by minimizing the sum of the squared differences between the left and right hand side of (11). 
permutations. Across the six permutations, $c$ averages 1.31 with the median equal to 1.37. Although no test for whether $c$ is significantly bigger than unity is available, these findings hint at the importance of a strategic cost generated by Rosca auctions.

For the second restricted specification, I fix $c$ at 1.5 and estimate $\phi_{K_{1}}$ and $\phi_{K_{2}}$. The results are set out in Table 7. In nine of twelve cases, $\phi$ is estimated positive, which suggests that bidders act, to some extent, altruistically. The mean and median of $\phi$ are 0.77 and 0.70 respectively, which suggests that, within this restricted framework, observed bids are closer to a scenario of truthful (that is bidding one's valuation) than income-maximizing bidding. Qualitatively, this result is robust to alternative choices of $c$ between 1 and 2.

\subsection{Parametric Analysis}

The non-parametric approach of the preceding subsection does not allow to exploit observable heterogeneity in the data. In this section, therefore, a parametric distribution of $R$ is hypothesized, which allows to account for observed group and auction-specific heterogeneity. In particular, when $R$ is exponentially distributed with a lower bound of unity and scale parameter $\theta, b_{K}^{a}(r)$ is linear in $r$ for all $K$ and thus easily invertible, which is essential for implementing a full-blown recursive structural model. To get a sense for how restrictive the assumption of an exponential distribution is, Figure 4 depicts empirical and fitted cdf's for wining bids in auctions with six and eight bidders, respectively. Notice that, since $b_{K}^{a}(r)$ is linear in $r$, bids in this model are distributed according to a two parameter exponential cdf. For the limited number of observations available, this model appears to provide a satisfactory fit.

For the subsequent analysis it will be assumed that all Rosca participants have an identical

discount rate $\delta$ and face the same cost of external funds $c$. I will allow, however, for the 
possibility that bids are not distributed identically across auctions in two ways. First, the distribution of bidders' profits may depend on observable group and auction-specific characteristics. To be precise, denote a winning bid in the data set by $b_{i}^{w}(i=1, \ldots, 149)$ and the associated group and auction-specific characteristics by the vector $x_{i}$. In the estimation, the distribution of profits may vary with $x_{i}$ through the scale parameter $\theta$. With a slight abuse of notation, this will be denoted by $\theta_{i}=\theta\left(x_{i}\right)$. Second, the nature of interdependence of bidders' preferences may also depend on $x_{i}$ through the interdependence parameter $\phi, \phi_{i}=\phi\left(x_{i}\right)$.

When $R$ is exponentially distributed, a bid $b_{i}$ is distributed according to a two-parameter exponential distribution with lower bound $\zeta_{K_{i}}\left(\theta\left(x_{i}\right), \phi\left(x_{i}\right)\right)$ and scale parameter $\xi_{K_{i}}\left(\theta\left(x_{i}\right), \phi\left(x_{i}\right)\right)$, where the functional forms of $\zeta_{K_{i}}\left(\right.$, ) and $\xi_{K_{i}}\left(\right.$, ) are determined by the functional form of $b_{K}^{a}()$. As $b_{i}^{w}$ is distributed as the second highest order statistic of a sample of $K_{i}$ bids which all share identical covariates $x_{i}$, the density of $b_{i}^{w}$ can be derived from $b_{i}$ 's exponential density through (13). The likelihood of the sample is obtained as the product of the individual $b_{i}^{w}$-densities. ${ }^{13}$ The parameters $c$ and $\delta$ as well as the parameters by which $\theta\left(x_{i}\right)$ and $\phi\left(x_{i}\right)$ are parameterized are

13 There are some additional wrinkles. First, in all 23 sample Roscas the organizer obtains the second pot without an auction. Second, in each round the organizer is entitled to a commission. In 14 of the 23 groups, this is a fraction of the pot amount, which ranges between 2.5 and 5 percent. In the remaining 9 groups, instead of a fixed commission, the organizer shares the winning bid with the losing bidders. All these features are incorporated in the structural econometric model. 
then estimated by maximum likelihood (ML). To avoid problems of non-regular ML estimation, all eight observations from auctions with only two bidders are dropped from this analysis. ${ }^{14}$

The results for five alternative specifications, in which $\theta\left(x_{i}\right)$ and $\phi\left(x_{i}\right)$ are linear functions of group and auction-specific characteristics set out in Table 1, are set out in Table 8. To provide a benchmark, the first two specifications do not account for heterogeneity across auctions. When, in addition, income-maximizing preferences are imposed, the discount factor for six months is estimated at $0.67, c$ is significantly bigger than unity and the average profit is 1.46 .

In specifications 2 through 5, the discount factor and the cost of external funds are robustly estimated at around 0.82 and 2, respectively. The estimate of the discount factor $\delta$ is well in line with village interest rates, where moneylenders charge a minimum of 3 percent per month. Notice that, as all payoffs in the data are in nominal terms, $\delta$ discounts nominal future income. When inflation (measured by the Tamil Nadu consumer price index for agricultural laborers, CPIAL) is taken into account, which averaged around ten percent per year between 1993 and 2000, one arrives at a real discount factor of 0.86 per six months.

Specification 5 includes both group and auction-specific characteristics. Accordingly, members of groups with a larger contribution observe a larger profit rate, while there is no significant evidence for different degrees of utility interdependence along this characteristic. A plausible explanation for this finding is that there are increasing returns to project size, while bidders who pay larger contributions do not act less altruistically.

${ }^{14}$ As the domain of $b_{i}^{w}$ depends on parameters that are to be estimated, the density of $b_{i}^{w}$ has to meet certain conditions at the support boundary (see Smith, 1985) for the resulting estimates to be normally distributed. These are met if, and only if, $K \geq 3$. 
Caste composition and organizer experience affect only altruism significantly, while the number of cycles a given group has completed previously affects in a significant way only the distribution of profits. As in the reduced-form analysis, no systematic differences arise by group duration. It should be noted in this connection that this analysis does not identify whether differences in expected profits and altruism in response to observed group characteristics are causal or due to selection. To give an example, the finding that bidding is more altruistic the more experienced the organizer can plausibly be explained in two ways. On the one hand, effective leadership, for which experience can be a proxy, may induce group members to act more altruistically and thus improves the group's welfare. On the other, a more experienced organizer may select members who act more altruistically into his groups.

Members of groups with a larger fraction of SC membership observe larger profits than members of groups dominated by non-SC villagers. ${ }^{15}$ This is in accordance with qualitative information provided by some of the organizers that the few SC villagers who join Roscas have typically experienced a rapid, recent rise in economic status. It is thus plausible that members of such groups observe higher profits. At the same time, bidding in mixed caste groups is significantly more altruistic than in groups dominated by non-SC members. According to the point estimate, for a group size of 10 , the interdependence parameter increases by 0.65 for each additional SC member. There is thus no evidence for a conflict potential arising from withingroup caste heterogeneity. In informal interviews, villagers from both ends of the caste spectrum

15 Recall that the mean of the caste variable in these data is 0.86 with a minimum of 0.3 . The coefficient is, therefore, driven by the difference between more diverse and predominantly non-SC groups. 
emphasized that inter-community relations had improved substantially during the 1990's. More altruistic behavior in more mixed groups may be an expression of the deliberate effort of villagers to avoid conflict and improve these relations. On the other hand, mixed caste groups may attract villagers who are more cooperatively oriented and thus also act more altruistically.

Turning to auction-specific characteristics, as expected, bidders observe higher returns in winter auctions. Bidding is more altruistic when information on the winner's purpose is public, which is mostly associated with an economic emergency (see Section 2). In principle, this finding supports the hypothesis that villagers deliberately bid less competitively when a bidder can claim an economic emergency. Each of these coefficients fails to be statistically significant at the ten percent level, however.

A comparison of the results in column 5 with those in columns 3 and 4 highlights the importance of simultaneously accounting for different aspects of observed heterogeneity in the data. For example, according to specification 4, altruism is significantly smaller in auctions with public information on the winner's purpose when group-specific characteristics are not included in the estimation.

\section{CONCLUDING REMARKS}

In this paper, I have used data from auctions in bidding Roscas to show how and to what extent altruism improves the quality of allocations generated by competitive bidding in a private information environment. To achieve this, the paper makes three original methodological contributions. First, a theoretical auction model is developed in which bidding creates a social cost, which in turn depends on the nature and extent of interdependence of bidders' preferences. Second, I derive a semi-parametric procedure, which delivers estimates of fundamental parameters of the theoretical auction model without making assumptions on the underlying 
stochastic process. Third, I conduct a parametric structural estimation of Rosca auctions, which accounts for several dimensions of observed heterogeneity present in the auction data.

Key empirical findings are that effective leadership is associated with higher welfare for the group's members and that welfare is also larger for groups that are more heterogeneous with respect to their members' caste affiliation. What this approach leaves open and deserves future research is to what extent these empirical relationships are causal or a result of selection.

The findings reported here contribute to our understanding of the design of a prominent savings and credit technology, and to the flexibility of non-market institutions more generally. Existing empirical studies of Roscas have established that a lottery assignment of ranks is wellsuited for overcoming commitment problems (Aliber, 2001; Gugerty, 2000) or resolving intrahousehold conflict (Anderson and Balland, 2002), while a fixed rank order may minimize enforcement problems (Anderson et al., 2004). In contrast, in the environment studied here, uncertainty and private information are the most salient features, and the use of concurrent auctions for the assignment of ranks can be viewed as the Rosca's institutional response to this set of market frictions.

\section{REFERENCES}

Aliber, M., 2001. Rotating savings and credit associations and the pursuit of self-discipline: A case study in South Africa. African review of money finance and banking 2003, 51-73.

Anderson, S., Balland, J. M., 2002. The economics of Roscas and intrahousehold resource allocation. Quarterly Journal of Economics 117 (3), 963-995.

Anderson, S., Baland, J. M., Moene, K. O., 2003. Sustainability and organizational design in informal groups, with some evidence from Kenyan Roscas. Working paper, University of Oslo.

Bajari, P., Hortacsu, A., 2005. Are structural estimates of auction models reasonable? Evidence from experimental data. Journal of Political Economy 113 (4), 703-741. 
Besley, T., Coate, S., Loury, G., 1993. The economics of rotating savings and credit associations. American Economic Review 83, 792-810.

Bulow, J., Huang, M., Klemperer, P., 1999. Toeholds and takeovers. Journal of Political Economy 107, 427-454.

Calomiris, C.W., Rajaraman, I., 1998. The role of ROSCAs: lumpy durables or event insurance? Journal of Development Economics 56 (1), 207-216.

Campo, S., 2005. Asymmetry and risk aversion within the independent private value paradigm. Manuscript, University of North Carolina at Chapel Hill.

Deltas, G., 2002. Determining damages from the operation of bidding rings: An analysis of the post-auction 'knockout sale’. Economic Theory 19, 243-269.

Engelbrecht-Wiggans, R., 1994. Auctions with price-proportional benefits to bidders. Games and Ecomomic Behavior 6, 339-346.

Fafchamps, M., Lund, S., 2003. Risk-sharing networks in rural Philippines. Journal of Development Economics 71, 261-287.

Ganga-Rao, S., 2001. Chits - User-friendly instrument, Vichithra Times, December 2001, p. 8.

Guerre, E., I. Perrigne and Q. Vuong, 2000. Optimal nonparametric estimation of first-price auctions. Econometrica 68, 525-574.

Gugerty, M. K., 2000. You can't save alone: testing theories of rotating savings and credit associations. Mimeo, Kennedy School of Government, Harvard University.

Handa, S., Kirton, C., 1999. The economics of rotating savings and credit associations: evidence from the Jamaican 'Partner'. Journal of Development Economics 60 (1), 173-194.

Jones, M. C., Marron, J. S., Sheather, S. J., 1996. A brief survey of bandwidth selection for density estimation. Journal of the American Statistical Association 91, 401-407.

Klonner, S., 2003. Rotating savings and credit associations with risk averse participants, International Economic Review 44 (3), 979-1005.

Kochar, A., 1999. Smoothing consumption by smoothing income: Hours-of-work responses to idiosyncratic agricultural shocks in rural India. Review of Economics and Statistics 81, 5061.

Kovsted, J., Lyk-Jensen, P., 1999. Rotating savings and credit associations: the choice between random and bidding allocation of funds. Journal of Development Economics 60 (1), 143172. 
Ledyard, J., 1995. Public goods: A survey of experimental research, in "Handbook of Experimental Economics” (J. Kagel and A. Roth, eds.), Princeton: Princeton University Press.

Ligon, E., 1998. Risk sharing and information in village economies. Review of Economic Studies 65, 847-864.

Pandey, Priyanka, 2004. Effects of technology on incentive design of share contracts. American Economic Review 94, 1152-1168.

Reserve Bank of India, 2000. Quarterly Banking Statistics, March 2000.

Rosenzweig, M., Binswanger, H., 1993. Wealth, weather risk, and the composition and profitability of agricultural investments. Economic Journal 103, 56-80.

Rosenzweig, M., Stark, O., 1989. Consumption smoothing, migration, and marriage: Evidence from rural India. Journal of Political Economy 97, 905-926.

Rosenzweig, M., Wolpin, K., 1989. Specific experience, household structure and intergenerational transfers: Farm family land and labor arrangements in developing countries. Quarterly Journal of Economics 100, 961-987.

Smith, R. L., 1985. Maximum likelihood estimation in a class of nonregular cases. Biometrika 72, 67-90.

Sobel, J., 2005. Interdependent preferences and reciprocity. Journal of Economic Literature 43, 392-436.

Townsend, R., 1994. Risk and insurance in village India. Econometrica 62, 539-591.

Udry, C., 1991. Rural credit in northern Nigeria: Credit as insurance in a rural economy. World Bank Economic Review 4, 251-269.

Udry, C., 1994. Risk and insurance in a rural credit market: An empirical investigation in northern Nigeria. Review of Economic Studies 61, 495-562.

Van Dillen, S., 2004. Different choices: assessing vulnerability in a south Indian village. Saarbruecken: Verlag fuer Entwicklungspolitik. 


\section{APPENDIX}

\section{Proof of Proposition 1}

Consider bidder 1 in an auction with $K$ bidders at the interim stage. Assume all other bidders bid according to the increasing bidding function $b_{K}() . U_{K}^{w}(\rho \mid r) \equiv r-c E\left[b_{K}\left(R_{K-1: K-1}\right) \mid R_{K-1: K-1}<\rho\right]$ is bidder 1's expected utility when she bids $b_{K}(\rho)$ and wins the auction, that is when $b_{K}(\rho)$ is the highest of the $K$ bids. Since $b_{K}()$ is increasing, the probability of this event is $P^{w}(\rho) \equiv P\left(R_{K-1: K-1} \leq \rho\right)=(F(\rho))^{K-1}$.

If bidder 1 bids $b_{K}(\rho)$ and this is the second highest bid submitted, her expected utility is $U_{K}^{l 1}(\rho) \equiv b_{K}(\rho) /(K-1)+\widetilde{\Pi}_{K}$. In this case, bidder 1's bid is the price the winner pays and this price is equally shared by the $K-1$ losers of this auction. The probability of this event is

$$
P^{l 1}(\rho) \equiv P\left(R_{K-1: K-1}>\rho \cap R_{K-2: K-1} \leq \rho\right)=(F(\rho))^{K-2}(K-1-(K-2) F(\rho))-(F(\rho))^{K-1} .
$$

Finally, if $b_{K}(\rho)$ is smaller than the second highest bid submitted, bidder 1's expected utility is $U_{K}^{l 2}(\rho) \equiv E\left[b_{K}\left(R_{K-2: K-1}\right) /(K-1) \mid R_{K-2: K-1}>\rho\right]+\widetilde{\Pi}_{K}$. The probability of this event is $P^{12}(\rho) \equiv P\left(R_{K-2: K-1}>\rho\right)=1-(F(\rho))^{K-2}(K-1-(K-2) F(\rho))$.

A necessary condition for a symmetric Bayesian-Nash equilibrium is that the derivative of

$$
U_{K}(\rho \mid r) \equiv U_{K}^{w}(\rho \mid r) P^{w}(\rho)+U_{K}^{l 1}(\rho) P^{l 1}(\rho)+U_{K}^{l 2}(\rho) P^{l 2}(\rho)
$$

with respect to $\rho$ evaluated at $\rho=r$ equal zero. This gives the following ordinary first-order differential equation,

$$
b_{K}{ }^{\prime}(r)(1-F(r))-f(r)\left((1+(K-1) c) b_{K}(r)-(K-1)\left(r-\widetilde{\Pi}_{K}\right)\right)=0,
$$

whose unique solution is $b_{K}^{e}(r)$. 


\section{Proof of Proposition 2}

Departing from (5), interim expected utility and the necessary condition for a symmetric Bayesian-Nash equilibrium are derived as in the proof of proposition 1 . The differential equation resulting now is

$$
\left(1-\phi_{K}\right)(1-F(r)) b_{K}{ }^{\prime}(r)-f(r)\left[(1+(K-1) c) b_{K}(r)-(K-1)\left(r-\widetilde{\Pi}_{K}\right)\right]=0,
$$

whose unique solution is $b_{K}^{a}(r)$. 
Table 1. Descriptive Statistics.

\begin{tabular}{|c|c|c|c|c|c|c|}
\hline \multirow[t]{2}{*}{ Unit of Observation } & \multicolumn{4}{|l|}{ Auction } & \multicolumn{2}{|c|}{ Group } \\
\hline & Mean & Std. & Minimum & Maximum & Mean & Std. \\
\hline \multicolumn{7}{|l|}{ Group Characteristics } \\
\hline Contribution per Round & $2,461.74$ & $1,544.37$ & 700 & 5000 & $2,682.61$ & $1,566.31$ \\
\hline Duration (in Rounds) & 11.80 & 2.43 & 10 & 17 & 11.17 & 1.95 \\
\hline Caste Composition* & 0.86 & 0.17 & 0.3 & 1 & 0.82 & 0.19 \\
\hline Previous Cycles** & 0.90 & 1.02 & 0 & 3 & 1.04 & 1.11 \\
\hline Organizer's Experience ${ }^{* * *}$ & 2.07 & 2.26 & 0 & 8 & 2.70 & 2.58 \\
\hline \multicolumn{7}{|l|}{ Auction Characteristics } \\
\hline Number of Bidders & 7.07 & 2.95 & 2 & 16 & & \\
\hline First Auction & 0.15 & 0.36 & 0 & 1 & & \\
\hline Winter Auction & 0.52 & 0.50 & 0 & 1 & & \\
\hline $\begin{array}{l}\text { Winner's Purpose Public } \\
\text { Information }{ }^{* * * *}\end{array}$ & 0.27 & 0.44 & 0 & 1 & & \\
\hline Observations & 149 & & & & 23 & \\
\hline
\end{tabular}

\footnotetext{
* Percentage of non-scheduled caste members in the group

** Number of cycles the same group completed previously

*** Number of Roscas the group’s organizer completed previously

**** Purpose of the auction's winner was known to other bidders before the auction
} 
Table 2. Use of Rosca Funds and Information Structure by Purpose Category.

\begin{tabular}{|c|c|c|c|c|}
\hline \multirow{3}{*}{ Purpose Category } & (1) & (2) & \multirow{3}{*}{$\begin{array}{l}(3) \\
\text { Total } \\
(1)+(2)\end{array}$} & \multirow{3}{*}{$\begin{array}{c}\text { (4) } \\
\text { Percentag } \\
\text { Publi } \\
\text { Informatior }\end{array}$} \\
\hline & \multicolumn{2}{|c|}{ Information } & & \\
\hline & private & public & & \\
\hline Agricultural Investment & 52 & 2 & 54 & 3.7 \\
\hline Non-agricultural Investment & 9 & 1 & 10 & 10.0 \\
\hline Investment into Housing & 12 & 6 & 18 & 33.3 \\
\hline Purchase of Durable, Non-productive Good & 3 & 2 & 5 & 40.0 \\
\hline Daughter's Marriage & 7 & 23 & 30 & 76.7 \\
\hline Consolidation of Existing Debt & 3 & 3 & 6 & 50.0 \\
\hline Other Consumptive Expenditures & 3 & 2 & 5 & 40.0 \\
\hline Unknown & 20 & 1 & 21 & 4.8 \\
\hline Total & 109 & 40 & 149 & 26.8 \\
\hline
\end{tabular}


Table 3. Use of Rosca Funds and Information Structure by Purpose.

\begin{tabular}{|c|c|c|c|c|c|}
\hline \multirow{3}{*}{ Purpose Category } & \multirow{3}{*}{ Purpose } & (1) & $(2)$ & \multirow{3}{*}{\multicolumn{2}{|c|}{$\begin{array}{l}(3) \\
\text { Total } \\
(1)+(2)\end{array}$}} \\
\hline & & \multicolumn{2}{|c|}{ Information } & & \\
\hline & & Private & Public & & \\
\hline \multirow{5}{*}{$\begin{array}{l}\text { Agricultural } \\
\text { investment }\end{array}$} & Purchase of field or oti (use right) & 36 & 2 & 38 & 25.5 \\
\hline & Purchase of bullocks or bullock cart & 4 & 0 & 4 & 2.7 \\
\hline & Purchase of milk animal & 4 & 0 & 4 & 2.7 \\
\hline & Startup of banana cultivation & 1 & 0 & 1 & 0.7 \\
\hline & Purchase of agricultural inputs & 7 & 0 & 7 & 4.7 \\
\hline \multirow{4}{*}{$\begin{array}{l}\text { Non-agricultural } \\
\text { investment }\end{array}$} & Startup of moneylender business & 4 & 0 & 4 & 2.7 \\
\hline & Startup or improvement of other non-agricultural business & 2 & 1 & 6 & 4.0 \\
\hline & Bribe for obtaining a public sector job & 2 & 0 & 2 & 1.3 \\
\hline & Financing of a village-level election campaign & 1 & 0 & 2 & 0.7 \\
\hline \multirow{3}{*}{$\begin{array}{l}\text { Investment into } \\
\text { Housing }\end{array}$} & Purchase of own house & 3 & 1 & 4 & 2.7 \\
\hline & Construction of own house & 7 & 1 & 8 & 5.3 \\
\hline & Renovation of own house & 2 & 4 & 6 & 4.0 \\
\hline \multirow{2}{*}{$\begin{array}{l}\text { Purchase of durable, } \\
\text { non-productive good }\end{array}$} & Motor bike & 0 & 1 & 1 & 0.7 \\
\hline & Jewels or household utensils for daughter & 4 & 1 & 5 & 2.7 \\
\hline \multirow[t]{2}{*}{ Marriage } & Daughter's marriage (function and dowry) & 5 & 14 & 19 & 12.8 \\
\hline & Other relative's marriage (sister, son, or participant himself) & 2 & 9 & 11 & 7.4 \\
\hline \multirow{2}{*}{$\begin{array}{l}\text { Consolidation of } \\
\text { existing debt }\end{array}$} & Consolidation of existing debt with moneylender & 2 & 3 & 5 & 3.4 \\
\hline & Release of field plot mortgaged to bank & 1 & 0 & 1 & 0.7 \\
\hline \multirow{4}{*}{$\begin{array}{l}\text { Other non-productive } \\
\text { expenditures }\end{array}$} & Daughter's puberty function & 0 & 1 & 1 & 0.7 \\
\hline & Compensation of income shortfall & 1 & 0 & 1 & 0.7 \\
\hline & Medical treatment of illness & 1 & 1 & 2 & 1.3 \\
\hline & Children's education & 1 & 0 & 1 & 0.7 \\
\hline Unknown & & 20 & 1 & 21 & 14.1 \\
\hline
\end{tabular}


Table 4. Reduced Form Analysis of Winning Bids. Dependent variable: Winning Bid as Percentage of Pot.

Est. $\quad$ Sterr. $^{\circ}$

\section{Group Characteristics}

Contribution (in Rs. 1,000)

$1.16 * * \quad 0.51$

Duration (in Rounds)

$0.27 \quad 0.26$

Caste Composition

$-5.46 \quad 3.83$

Previous Cycles

$-2.21 * * \quad 0.96$

Organizer's Experience

$-0.52 \quad 0.46$

$\underline{\text { Auction Characteristics }}$

Number of Bidders

$4.05 * * * \quad 0.21$

First Auction

3.52 * $\quad 1.90$

Winter Auction

$1.57 \quad 1.23$

Winner's Purpose Public Information

$-2.67 * \quad 1.49$

Intercept

$3.05 \quad 5.16$

R-Squared

0.77

Number of observations

149

o obtained from White's (1980) heteroskedacticity-consistent covariance matrix estimator

* significant at $10 \%$ level

** significant at 5\% level

*** significant at $1 \%$ level 
Table 5. Nonparametric Structural Estimation with Alternative Numbers of Bidders.*

\begin{tabular}{llrrr}
$\begin{array}{l}\text { Number } \\
\text { of bidders }\end{array}$ & 6 & 7 & 8 \\
\hline 5 & $c$ & -0.15 & -0.11 & 0.06 \\
& $\Delta_{\widetilde{\Pi}}$ & 0.04 & 0.01 & 0.00 \\
& $\phi_{K_{1}}$ & 0.70 & 0.96 & 0.96 \\
& $\phi_{K_{2}}$ & 0.89 & 0.93 & 0.89 \\
6 & $c$ & & -0.03 & -0.21 \\
& $\Delta_{\widetilde{\Pi}}$ & & -0.02 & -0.01 \\
& $\phi_{K_{1}}$ & & 0.95 & 0.96 \\
& $\phi_{K_{2}}$ & & 0.83 & 0.82 \\
& $c$ & & & -0.39 \\
& $\Delta_{\widetilde{\Pi}}$ & & & 0.02 \\
& $\phi_{K_{1}}$ & & & 1.16 \\
& $\phi_{K_{2}}$ & & & 1.21 \\
\hline
\end{tabular}

* Equation (11) is evaluated at $q$ equal to $0.4,0.5,0.6,0.7$ 
Table 6. Nonparametric Structural Estimation with no Preference-Interdependence.

\begin{tabular}{llrrr}
$\begin{array}{l}\text { Number } \\
\text { of bidders }\end{array}$ & 6 & 7 & 8 \\
\hline 5 & $c$ & -0.02 & 0.52 & 3.20 \\
& $\Delta_{\widetilde{\Pi}}$ & 0.04 & -0.01 & -0.15 \\
6 & $c$ & & 1.37 & 1.73 \\
& $\Delta_{\widetilde{\Pi}}$ & & -0.05 & -0.10 \\
7 & $c$ & & & 1.03 \\
& $\Delta_{\widetilde{\Pi}}$ & & & -0.03
\end{tabular}

Table 7. Nonparametric Structural Estimation with $c=1.5$.

\begin{tabular}{llrrr}
$\begin{array}{l}\text {l} \text { Number } \\
\text { of bidders }\end{array}$ & 6 & 7 & 8 \\
\hline 5 & $\Delta_{\widetilde{\Pi}}$ & -0.41 & -0.06 & -0.09 \\
& $\phi_{K_{1}}$ & 3.90 & 0.91 & 1.08 \\
& $\phi_{K_{2}}$ & 1.59 & 0.72 & 0.75 \\
6 & $\Delta_{\widetilde{\Pi}}$ & & -0.13 & -0.16 \\
& $\phi_{K_{1}}$ & & 0.68 & 0.47 \\
& $\phi_{K_{2}}$ & & 0.10 & -0.11 \\
7 & $\Delta_{\widetilde{\Pi}}$ & & & -0.08 \\
& $\phi_{K_{1}}$ & & & -0.30 \\
& $\phi_{K_{2}}$ & & & -0.56 \\
\hline
\end{tabular}


Table 8. Parametric Structural Estimation.

(1)

(2)

(3)

(4)

(5)

\begin{tabular}{|c|c|c|c|c|c|c|c|c|c|c|}
\hline Parameter & Est. & Sterr. ${ }^{\#}$ & Est. & Sterr. & Est. & Sterr. & Est. & Sterr. & Est. & Sterr. \\
\hline$\delta$ & $0.674 * * *$ & 0.045 & $0.818 * * *$ & 0.028 & $0.813 * * *$ & 0.032 & $0.809 * * *$ & 0.036 & $0.816^{* * *}$ & 0.034 \\
\hline$c$ & $2.94 * * *$ & 0.378 & $2.057 * * *$ & 0.322 & $1.827^{* * *}$ & 0.290 & $2.087 * * *$ & 0.398 & $1.809 * * *$ & 0.311 \\
\hline$\theta$ & $0.457 * * *$ & 0.070 & $0.321 * * *$ & 0.053 & $0.401 * * *$ & 0.109 & $0.323 * * *$ & 0.066 & $0.387^{* * *}$ & 0.129 \\
\hline$\phi$ & & & $-3.427 * * *$ & 0.516 & $3.594 * * *$ & 0.936 & $-3.025^{* * *}$ & 0.649 & 3.076 & 3.717 \\
\hline \multicolumn{11}{|l|}{ Group Characteristics } \\
\hline$\theta$ - Contribution & & & & & $0.028 * * *$ & 0.011 & & & $0.027 * *$ & 0.011 \\
\hline$\phi$-Contribution & & & & & -0.065 & 0.145 & & & -0.110 & 0.247 \\
\hline$\theta$ - Duration & & & & & -0.001 & 0.006 & & & 0.000 & 0.006 \\
\hline$\phi$ - Duration & & & & & $-0.170 * *$ & 0.084 & & & -0.103 & 0.153 \\
\hline$\theta$ - Caste Composition & & & & & -0.153 & 0.098 & & & -0.162 & 0.113 \\
\hline$\phi$-Caste Composition & & & & & $-5.471 * * *$ & 1.189 & & & $-6.526^{* *}$ & 2.908 \\
\hline$\theta$ - Previous Cycles & & & & & $-0.065^{* *}$ & 0.026 & & & $-0.060 * *$ & 0.026 \\
\hline$\phi$ - Previous Cycles & & & & & $-0.529 *$ & 0.312 & & & -0.717 & 0.602 \\
\hline$\theta$ - Organizer Experience & & & & & 0.006 & 0.013 & & & 0.004 & 0.012 \\
\hline$\phi$-Organizer Experience & & & & & $0.698 * * *$ & 0.185 & & & $0.808^{* * *}$ & 0.266 \\
\hline \multicolumn{11}{|l|}{ Auction Characteristics } \\
\hline$\theta$ - Winter Auction & & & & & & & 0.017 & 0.019 & 0.022 & 0.021 \\
\hline$\phi$-Winter Auction & & & & & & & -0.119 & 0.280 & 0.513 & 1.167 \\
\hline$\theta$ - Public Information & & & & & & & $-0.045^{*}$ & 0.024 & -0.004 & 0.023 \\
\hline$\phi$ - Public Information & & & & & & & $-1.248^{* *}$ & 0.567 & 0.974 & 1.272 \\
\hline Number of Observations & 141 & & 141 & & 141 & & 141 & & 141 & \\
\hline Log-Likelihood & -1274 & & -1269 & & -1243 & & -1267 & & -1241 & \\
\hline
\end{tabular}

\# calculated from empirical Hessian 
Figure 1. Mean, Minimum and Maximum Winning Bid by Number of Bidders.*

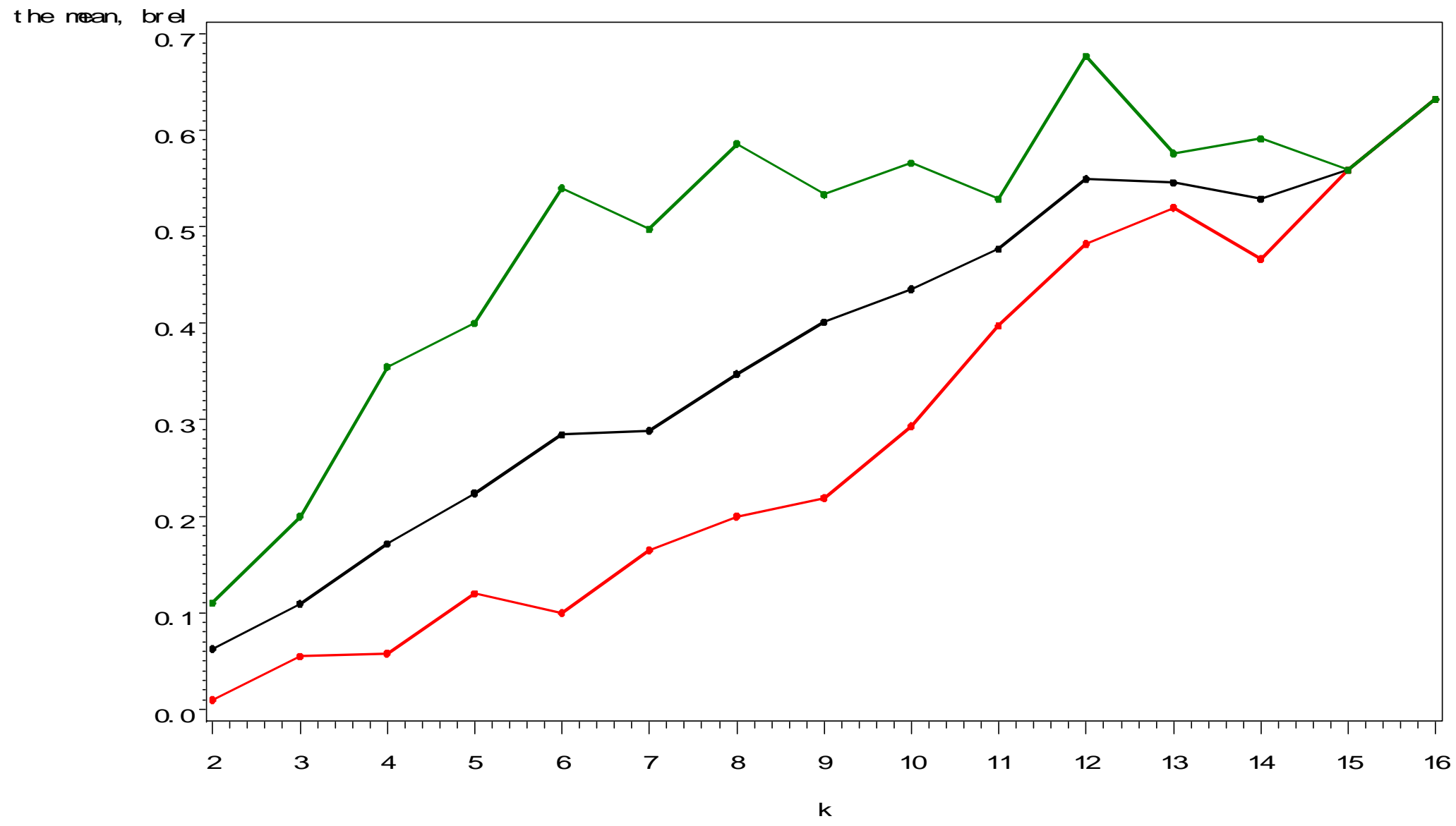

* Horizontal axis: number of bidders; vertical axis: winning bid relative to pot $(\mathrm{b} / \mathrm{mn})$ 
Figure 2. Equilibrium Bidding Function with Spiteful $(\mu=-0.5)$, Income-maximizing $(\mu=0)$ and Altruistic $(\mu=0.5)$ Bidders.

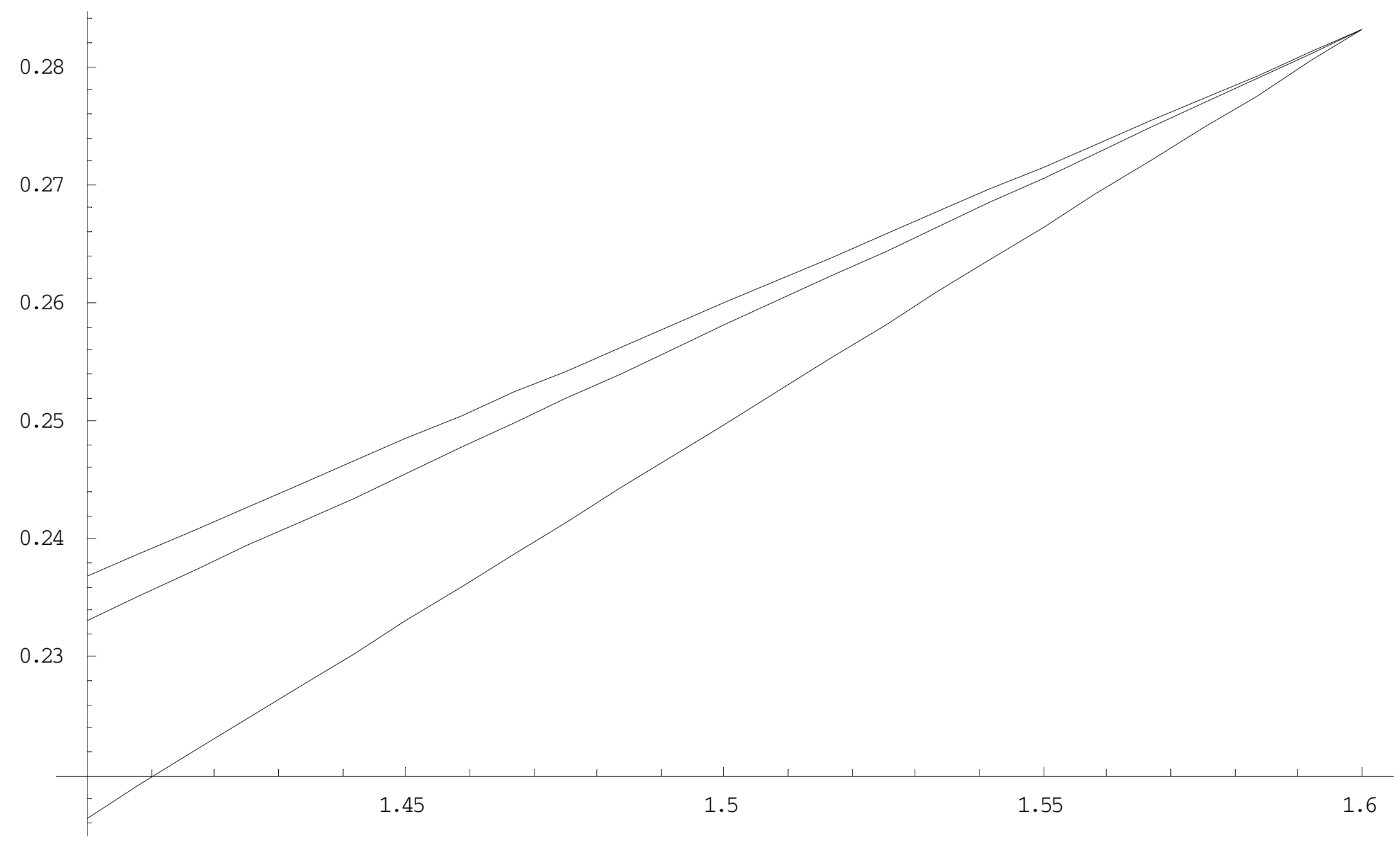


Figure 3. Kernel Density Estimates of Winning Bids for Auctions with six (solid line) and eight Bidders (dashed line).*

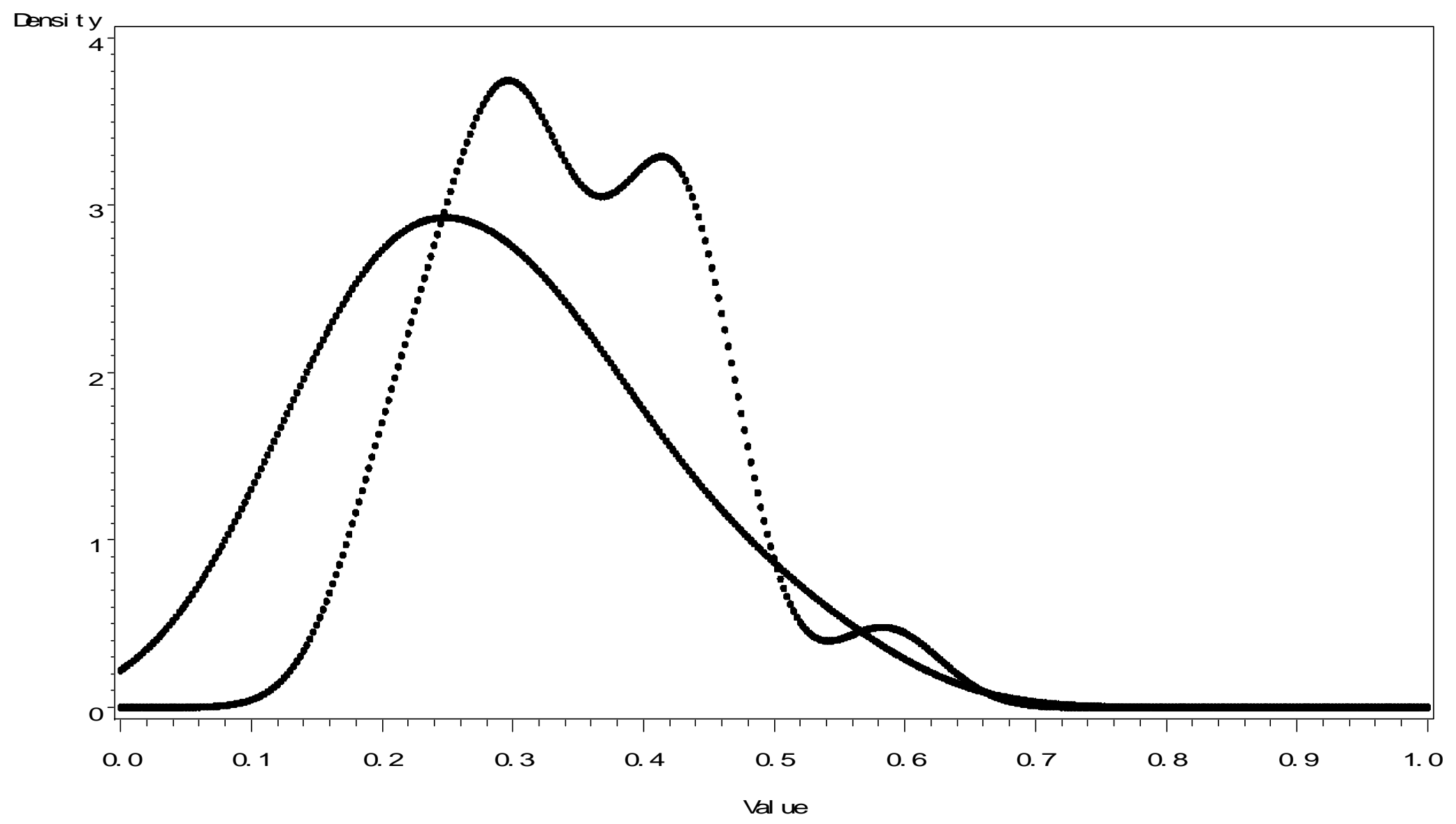

* Horizontal axis: winning bid relative to pot (b/mn); Gaussian kernel, bandwidth computed by Sheather and Jones’ plug in formula (see Jones et al., 1996) 
Figure 4. Empirical and Fitted Cumulative Distribution Function of the Winning Bid for Auctions with six (upper panel) and eight Bidders (lower panel).*

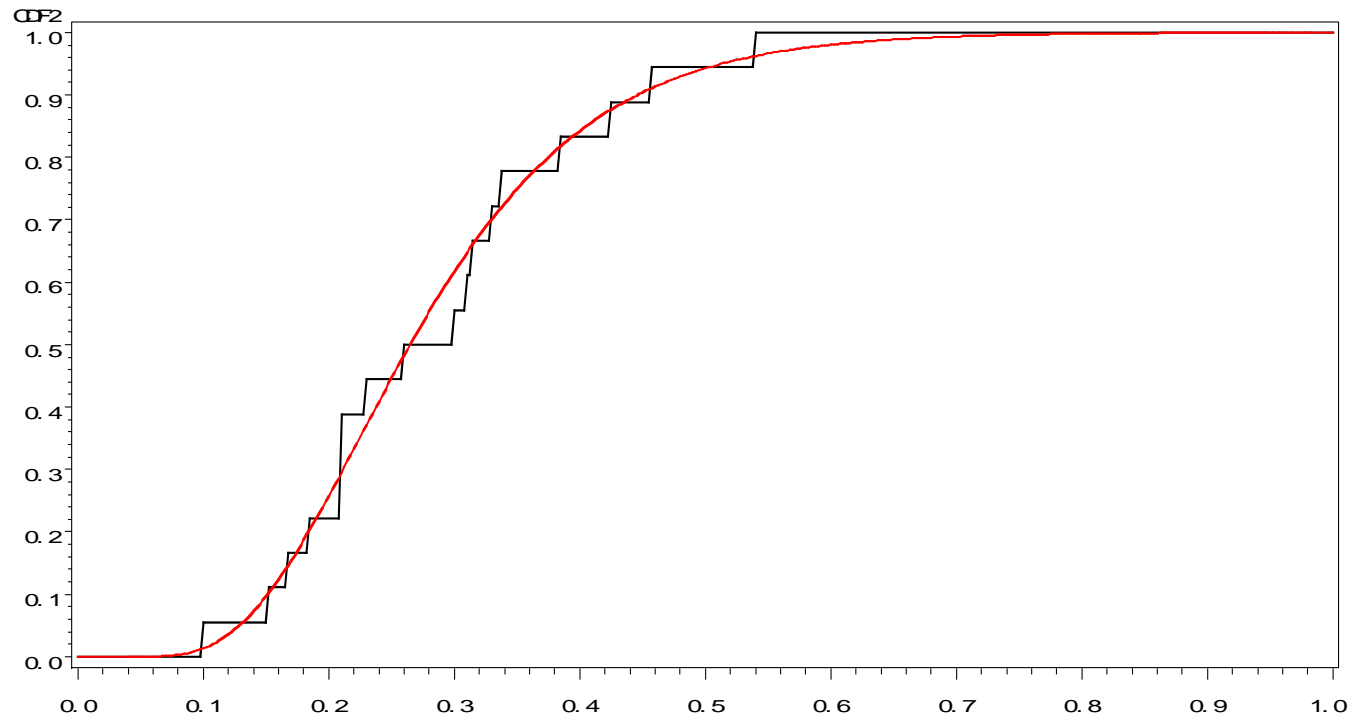

B1

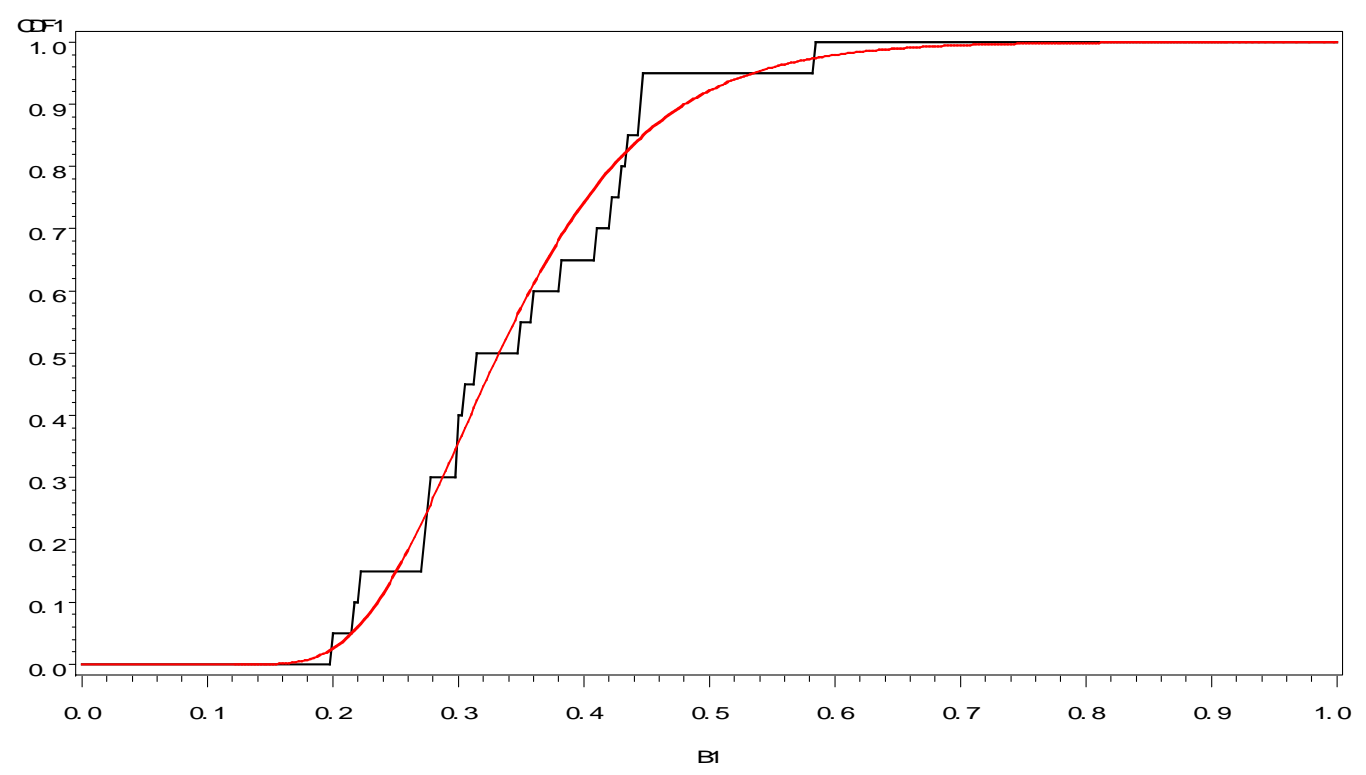

* The fitted cdf is the cdf of the second highest order statistic of a sample of size $k$, where $k$ is the number of bidders, and each bid is assumed to be distributed according to a two-parameter exponential distribution. Parameters are estimated by maximum likelihood. 